\title{
O perfil docente no ensino superior privado e o desempenho no Enade
}

\author{
Alboni Marisa Dudeque Pianovski Vieirai \\ Pontifícia Universidade Católica do Paraná, Curitiba, PR, Brasil \\ Daniel Schneikeri(i) \\ Pontifícia Universidade Católica do Paraná, Curitiba, PR, Brasil
}

\begin{abstract}
Resumo
O artigo tem por objetivo relacionar características do perfil da docência no ensino superior ao desempenho acadêmico dos estudantes de instituições de ensino superior privadas, medido pela média do conceito recebido no Exame Nacional de Desempenho dos Estudantes. Trata-se de estudo descritivo, utilizando dados do referido exame (2016 e 2017) e microdados dos docentes e instituições de ensino superior (2016 e 2017) do Instituto Nacional de Estudos e Pesquisas Educacionais Anísio Teixeira, em que se verificou o impacto de diversas variáveis na média do Exame Nacional de Desempenho dos Estudantes por instituição. Foi aplicada uma regressão linear múltipla, a partir da qual se encontrou que os fatores positivos mais significantes estão relacionados ao grau de escolaridade da docência. Os resultados indicaram também que o regime de trabalho dos docentes não demonstrou ser uma variável que agrega valor ao desempenho dos estudantes no mencionado exame.
\end{abstract}

Palavras-chave

Docência. Enade. Instituições de ensino superior.

\section{Teaching profile in private higher education and Enade performance}

\begin{abstract}
The article aims to relate characteristics of the teacher profile in higher education to the academic performance of students from private higher education institutions, measured by the average of the concept received in the National Student Performance Exam. This is a descriptive study, using data from said exam (2016 and 2017) and microdata from teachers and higher education institutions (2016 and 2017) from the National Institute of Educational Studies and Research Anísio Teixeira, in which we verified the impact of several variables in the average of the National Student Performance Exam by institution. Multiple linear regression was applied, from which it was found that the most significant positive factors are related to the education level of teachers. The results also indicated that the teachers' work regime did not prove to be a variable that adds value to the students' performance in the aforementioned exam.
\end{abstract}

\section{Keywords}

Teaching. Enade. Higher education institutions. 


\title{
El perfil docente em educación superior privada y el desempeño em el Enade
}

\begin{abstract}
Resumen
El artículo tiene como objetivo relacionar características del perfil docente en la educación superior con el rendimiento académico de los estudiantes de instituciones privadas de educación superior, medido por el promedio del concepto recibido en el Examen Nacional de Desempeño del Estudiante. Se trata de un estudio descriptivo, utilizando datos de dicho examen (2016 y 2017) y microdatos de docentes e instituciones de educación superior (2016 y 2017) del Instituto Nacional de Estudios e Investigaciones Educativas Anísio Teixeira, en el que se analiza el impacto de varias variables en la promedio del Examen Nacional de Desempeño de Estudiantes por institución. Se aplicó regresión lineal múltiple, a partir de la cual se encontró que los factores positivos más significativos están relacionados con el grado de docencia. Los resultados también indicaron que el régimen de trabajo de los docentes no resultó ser una variable que agregue valor al desempeño de los estudiantes en el examen mencionado.
\end{abstract}

\section{Palabras clave}

Docencia. Enade. Instituciones de educación superior.

\section{Introdução}

O desempenho de estudantes, aferido de forma quantitativa, pode estar associado a vários fatores verificados na literatura: ao próprio aluno (por conta de fatores cognitivos e sociais), à instituição e aos docentes.

A compreensão dos atributos da docência no desempenho dos estudantes é relevante para a educação, uma vez que é por meio dela que se pode entender melhor como o perfil de um docente pode estar relacionado à qualidade do ensino e à transmissão e absorção de conhecimento. Do ponto de vista da gestão, essa compreensão é relevante aos administradores do ensino superior privado, uma vez que aponta variáveis nas quais a gestão de recursos humanos deveria focar.

A pesquisa tem por objetivo apresentar um estudo descritivo que relaciona características do perfil da docência no ensino superior ao desempenho acadêmico dos estudantes de instituições de ensino superior (IES) privadas, medido pela média do conceito Exame Nacional de Desempenho dos Estudantes (Enade) por instituição. Para se chegar aos resultados, foram utilizados dados do Enade (2016 e 2017) e microdados dos docentes e IES (2016 e 2017) do Instituto Nacional de Estudos e Pesquisas Educacionais Anísio Teixeira (Inep). Algumas variáveis das IES também foram incluídas, de forma a capturar alguma influência da instituição. 
Em relação à temática, podem-se citar os estudos adiante mencionados, que atribuem parte do desempenho dos estudantes às características da docência. Miranda (2011) utilizou um questionário baseado nos fatores que caracterizam a qualificação dos docentes e aplicou-o aos coordenadores do curso de Ciências Contábeis de 218 instituições. Como desempenho acadêmico dos discentes, foi utilizada a nota do Enade. Os fatores de qualificação dos docentes levados em conta foram: qualificação acadêmica (preparação do docente para a pesquisa), qualificação profissional (ligação do docente com as práticas profissionais existentes no mercado) e qualificação pedagógica (preparação para o exercício da docência). Assim, o autor pesquisou qual a relação existente entre desempenho discente e qualificação docente dos cursos de Ciências Contábeis no Brasil. Como conclusão, Miranda (2011) apontou que os alunos que apresentaram melhor desempenho no Enade foram aqueles que tiveram os professores com melhores níveis de qualificação. Especificamente, a qualificação acadêmica é a única que teve relação significativamente positiva na nota do Enade. Segundo o autor, as IES devem investir nas titulações de seu corpo docente, para alavancar os resultados acadêmicos de seus discentes. Já a qualificação pedagógica, contrariando o que a literatura mencionava, não exibiu relação significativa na nota do Enade e, portanto, no desempenho acadêmico dos discentes.

Miranda et al. (2015) mapearam variáveis presentes na literatura que afetam o desempenho acadêmico dos discentes da área de negócios (Administração, Ciências Contábeis e Economia). Como resultado, os autores concluíram que existem quatro variáveis de formação acadêmica do corpo docente que influenciam significativamente o desempenho acadêmico dos discentes: dedicação exclusiva, titulação (stricto sensu), publicações relevantes e estratégias ou métodos de ensino e aprendizagem. A estratégia de ensino teria maior grau de significância no desempenho dos discentes porque aparece com maior frequência nos trabalhos que revisaram. Segundo Miranda et al. (2015), existem poucos estudos sobre a relação entre desempenho acadêmico e corpo docente, o que dificultaria o estabelecimento de tendências com relação ao comportamento e à influência dessas variáveis. Porém, apontam que o professor tem papel significativo no processo de ensino e aprendizagem, assim como seu planejamento no exercício da docência. Os autores fazem ainda citação a outros estudiosos, como Glewwe et al. (2011) e Pil e Leana (2009), que encontraram relação 
entre desempenho acadêmico e corpo docente, mencionando variáveis específicas sobre os docentes, tais como: titulação, formação pedagógica, experiência profissional, regime de trabalho, entre outras.

Brito (2015) inicia seu estudo mencionando o impacto do crescimento quantitativo dos cursos de graduação no Brasil e questiona a qualidade deles, visto que um ensino superior de qualidade está relacionado ao crescimento da economia de um país. Relata que essa expansão de educação superior pode ter possibilitado ensino de baixa qualidade e aponta que é de extrema importância para o processo de ensino e aprendizagem conhecer a influência dos recursos que são disponibilizados à educação superior. Com base nesse contexto, Brito (2015) realizou um estudo no ensino de Administração, que teve uma expansão significativa, e verificou qual a relação entre o desempenho discente e o nível de escolaridade, além de condições de trabalho do corpo docente da instituição. O objetivo foi determinar como as características do corpo docente de uma IES influenciaram o desempenho dos alunos que concluíam os cursos de Administração no Enade. Para o estudo, foram utilizados microdados do Enade e do Censo da Educação Superior (ambos de 2012) de diferentes IES públicas e privadas no Brasil. Os resultados mostraram que o nível de escolaridade do corpo docente, a quantidade de docentes por curso e o volume de cursos ofertados pelas IES têm impacto significativo no desempenho dos discentes. A proporção de docentes com doutorado tem impacto positivo no desempenho dos estudantes e o regime de dedicação integral do corpo docente tem impacto positivo e relevante nas IES públicas.

Ferreira (2015) realizou um estudo para avaliar os discentes dos cursos de Contabilidade no Brasil, em face do aumento da disponibilidade no número de cursos e de vagas ofertadas, bem como da mudança ocorrida no padrão da Contabilidade no Brasil. Ferreira (2015) cita que a qualificação do corpo docente para formar esse novo perfil de discente apresenta-se como um desafio. Em sua pesquisa, confirmou que o desempenho acadêmico dos universitários está relacionado ao resultado deles no Enade e que o desempenho em questão é influenciado por diversas variáveis, sendo uma delas o corpo docente. Em seus resultados, encontrou correlação positiva entre a qualificação acadêmica do corpo docente e o desempenho acadêmico do alunado, ou seja, quanto mais professores com mestrado ou doutorado, melhor o desempenho acadêmico dos 
alunos. A autora também menciona que os próprios universitários relatam que as características das IES e seu corpo docente são de extrema importância para um bom resultado no Enade.

Souza e Moura (2017) tiveram como objetivo em seu trabalho avaliar o desempenho acadêmico no Enade dos alunos egressos do curso de Administração de IES públicas. Para realizar o estudo, utilizaram regressão linear múltipla. Concomitantemente com o que a literatura vem apresentando, os resultados obtidos pelos autores mostraram que o desempenho de um estudante é mais influenciado por sua formação anterior do que pelos recursos educacionais a que ele está exposto, porém, apesar de menor a relevância dos fatores educacionais, apontam que o percentual de professores doutores e o regime de trabalho deles são relevantes para o desempenho dos universitários. Souza e Moura (2017) indicam que, no que se refere ao curso de Administração, aumentar as exigências das políticas públicas quanto aos parâmetros de organização didático-pedagógica, formação docente, regime de trabalho parcial ou integral terá resultados positivos no desempenho dos estudantes no Enade.

Os dados utilizados na presente pesquisa são do Inep, que é uma autarquia federal voltada ao desenvolvimento econômico e social por meio de sua atuação em políticas educacionais. O Inep elabora o Enade e faz pesquisas, dentre elas, o Censo da Educação Superior.

O conceito Enade é utilizado neste trabalho como medida para quantificar o desempenho dos estudantes. De forma resumida, o conceito Enade é um indicador que mede a qualidade dos cursos das instituições, por meio de um exame realizado por pelo menos dois estudantes concluintes dos cursos (INEP, 2018).

Os dados referentes aos docentes e às instituições estão contidos no Censo da Educação Superior e dizem respeito ao menor nível de desagregação dos dados de docentes e instituições das pesquisas do Inep. Os microdados do Inep revelam detalhes da docência e das IES, bem como dos educandos, que vão muito além do que foi aproveitado para este estudo. 


\section{Metodologia}

Quanto aos procedimentos metodológicos, a pesquisa é bastante precisa. Por ser um estudo descritivo e utilizar parâmetros objetivos, os resultados podem ser facilmente reproduzidos.

Todos os dados necessários foram obtidos pelo site do Inep: o conceito Enade de 2016 (INEP, 2017) e 2017 (INEP, 2018) e os microdados do Censo da Educação Superior de 2016 (INEP, 2017) e 2017 (INEP, 2018). Como o objetivo é avaliar a relevância de características no perfil da docência de IES privadas, foi necessário agregar os dados por instituição privada.

Os quantitativos pesquisados foram os seguintes: para o ano de 2016, 811 instituições, sendo 134 centros universitários, 589 faculdades e 88 universidades; para o ano de 2017, foram 1.226 instituições, sendo 175 centros universitários, 958 faculdades e 93 universidades. Logo, a regressão com os dois anos combinados foi feita com 2.037 registros, sendo 309 referentes a centros universitários, 1.547 referentes a faculdades e 181 referentes a universidades. Obviamente, muitas instituições estão duplicadas na regressão, porque o que diferencia um registro de outro, para uma mesma instituição, é 0 ano ao qual aqueles dados se referem. Assim, um registro na regressão refere-se aos dados do par "instituição, ano".

Para o conceito Enade, que é a variável dependente da análise, utilizou-se a média do conceito Enade (contínuo) dos cursos que fazem parte de cada instituição. Esse agrupamento se deu pelo código da IES.

Em relação aos microdados, dentre os vários tipos de variáveis existentes, foram considerados, nesse ponto, somente aquelas pertencentes às características da docência. Inicialmente, separaram-se os docentes que pertenciam a instituições que se enquadravam nas categorias administrativas 4 e 5, conforme código do Inep, ou seja, docentes de instituições privadas com e sem fins lucrativos. Como as variáveis disponíveis referem-se a cada docente, novamente foi necessário criar um agrupamento dos docentes por instituição. Dessa forma, as variáveis independentes escolhidas, sumarizadas por IES, foram as seguintes: percentual de docentes em exercício; percentual de docentes com mestrado; percentual de docentes com doutorado; percentual de docentes com regime de trabalho em tempo integral; idade média dos 
docentes; existência de docentes com deficiência; percentual de docentes que atuam no ensino em cursos a distância; percentual de docentes que atuam em atividades de extensão; percentual de docentes que atuam em atividades de gestão, planejamento e avaliação; percentual de docentes que atuam em atividades de ensino em cursos de graduação presencial; percentual de docentes que atuam em atividades de ensino em pós-graduação stricto sensu presencial; percentual de docentes que atuam em pesquisa no âmbito de projetos e programas da IES; e percentual de docentes que possuem bolsa de pesquisa. Com exceção da variável que indica se há docentes com deficiência, que é uma variável dummy, todas as outras variáveis são quantitativas contínuas.

Consideraram-se ainda outras variáveis dummies, das próprias IES, como fatores que pudessem explicar o desempenho no conceito Enade e que não viessem do perfil da docência. A partir dos microdados do Inep, obtiveram-se as seguintes variáveis referentes às instituições: a organização acadêmica (dummy para cada tipo de organização - universidade, centro universitário ou faculdade); se as bibliotecas da IES têm acesso ao portal da Coordenação de Aperfeiçoamento de Pessoal de Nível Superior (Capes) de periódicos; se as bibliotecas da IES têm acesso a outras bases de dados licenciadas ou compradas; e se as bibliotecas da IES oferecem serviços pela internet.

As informações do Censo do Ensino Superior de 2016 foram utilizadas como variáveis explicativas para a média do Enade de 2016, bem como ocorreu para as informações de 2017. Optou-se por utilizar os dois anos em conjunto na regressão para que se obtivessem resultados mais robustos, que fossem estáveis ao longo de pelo menos dois anos. A regressão para um ano poderia revelar características específicas apenas para determinado ano. Idealmente, como sugestão para comparações em pesquisas futuras, poder-se-ia considerar intervalos de tempos até maiores.

De posse de todas as variáveis, procedeu-se a uma regressão linear múltipla no intuito de se verificar como cada variável está associada à média do conceito Enade em cada instituição. A análise dos coeficientes da regressão permite compreender como um aumento ou diminuição, em cada variável, produziria resultado no conceito Enade.

O Fonte: Os autores (2019). traz um resumo de todas as variáveis envolvidas na regressão. Cada variável diz respeito às informações por IES privadas e por ano (2016 ou 2017). 
Quadro 1 - Variáveis da regressão linear

\begin{tabular}{|c|c|c|}
\hline Código da Variável & Descrição & Tipo \\
\hline media.enade & $\begin{array}{l}\text { Variável dependente, média do conceito Enade por } \\
\text { IES }\end{array}$ & Quantitativa \\
\hline pct.ex & Percentual de docentes em exercício & Quantitativa \\
\hline pct.mest & Percentual de docentes com mestrado & Quantitativa \\
\hline pct.dr & Percentual de docentes com doutorado & Quantitativa \\
\hline pct.regime.t.integral & $\begin{array}{c}\text { Percentual de docentes com regime de trabalho em } \\
\text { tempo integral }\end{array}$ & Quantitativa \\
\hline idade.media & Idade média dos docentes & Quantitativa \\
\hline def & Existência de docentes com deficiência & Dummy \\
\hline pct.atu.ead & $\begin{array}{c}\text { Percentual de docentes que atuam no ensino em } \\
\text { cursos a distância }\end{array}$ & Quantitativa \\
\hline pct.atu.extensao & $\begin{array}{l}\text { Percentual de docentes que atuam em atividades } \\
\text { de extensão }\end{array}$ & Quantitativa \\
\hline pct.atu.gestao & $\begin{array}{c}\text { Percentual de docentes que atuam em atividades } \\
\text { de gestão, planejamento e avaliação }\end{array}$ & Quantitativa \\
\hline pct.atu.grad.presencial & $\begin{array}{l}\text { Percentual de docentes que atuam em atividades } \\
\text { de ensino em cursos de graduação presencial }\end{array}$ & Quantitativa \\
\hline pct.atu.strictu.pres & $\begin{array}{l}\text { Percentual de docentes que atuam em atividade de } \\
\text { ensino em pós-graduação stricto sensu presencial }\end{array}$ & Quantitativa \\
\hline pct.atu.pesquisa & $\begin{array}{l}\text { Percentual de docentes que atuam em pesquisa no } \\
\text { âmbito de projetos e programas da IES }\end{array}$ & Quantitativa \\
\hline pct.bolsa.pesquisa & $\begin{array}{c}\text { Percentual de docentes que possuem bolsa de } \\
\text { pesquisa }\end{array}$ & Quantitativa \\
\hline org.acad.cu & Se é centro universitário & Dummy \\
\hline org.acad.fac & Se é faculdade & Dummy \\
\hline bib.portal.capes & $\begin{array}{c}\text { Se as bibliotecas da IES têm acesso ao portal } \\
\text { Capes de periódicos }\end{array}$ & Dummy \\
\hline bib.outras.bases & $\begin{array}{c}\text { Se as bibliotecas da IES têm acesso a outras } \\
\text { bases de dados licenciadas ou compradas }\end{array}$ & Dummy \\
\hline bib.servico.internet & $\begin{array}{l}\text { Se as bibliotecas da IES oferecem serviços pela } \\
\text { internet }\end{array}$ & Dummy \\
\hline
\end{tabular}

Fonte: Os autores (2019).

Com exceção da idade média dos docentes, todas as variáveis independentes situam-se num intervalo entre 0 e 1 , considerando que variáveis dummies (falso/verdadeiro) podem ser mapeadas como 0 ou 1. Por esse motivo, a variável representativa da idade média foi normalizada no intervalo entre 0 e 1 . Assim, a regressão final considera informações que se situam na mesma escala, fazendo com que os coeficientes possam ser comparados diretamente.

Para se chegar à base de dados necessária, utilizaram-se apenas informações constantes nas três fontes de dados, ou seja, instituições que estavam presentes nos dados do Enade e que estavam presentes tanto nos microdados das IES quanto nos dos docentes. 


\section{Resultados e discussão}

Numa análise preliminar dos dados, agregados por ano (Erro! Fonte de referência não encontrada.), podem-se observar algumas características.

Tabela 1 - Resumo das variáveis

\begin{tabular}{c|ccc|ccc}
\hline & \multicolumn{3}{|c|}{$\mathbf{2 0 1 6}$} & & $\mathbf{2 0 1 7}$ \\
\hline Variável & Média & Mínimo & Máximo & Média & Mínimo & Máximo \\
\hline media.enade & 2,16 & 0,00 & 5,00 & 2,09 & 0,00 & 4,80 \\
pct.ex & $98 \%$ & $40 \%$ & $100 \%$ & $98 \%$ & $58 \%$ & $100 \%$ \\
pct.mest & $48 \%$ & $10 \%$ & $87 \%$ & $50 \%$ & $0 \%$ & $100 \%$ \\
pct.dr & $18 \%$ & $0 \%$ & $84 \%$ & $18 \%$ & $0 \%$ & $95 \%$ \\
pct.regime.t.integral & $22 \%$ & $0 \%$ & $93 \%$ & $20 \%$ & $0 \%$ & $100 \%$ \\
idade.media & 42,1 & 33,7 & 57,1 & 43,2 & 33,6 & 61,1 \\
def & $41 \%{ }^{*}$ & - & - & $33 \%{ }^{*}$ & - & - \\
pct.atu.ead & $2 \%$ & $0 \%$ & $96 \%$ & $2 \%$ & $0 \%$ & $100 \%$ \\
pct.atu.extensao & $27 \%$ & $0 \%$ & $100 \%$ & $26 \%$ & $0 \%$ & $100 \%$ \\
pct.atu.gestao & $22 \%$ & $0 \%$ & $100 \%$ & $23 \%$ & $0 \%$ & $100 \%$ \\
pct.atu.grad.presencial & $96 \%$ & $29 \%$ & $100 \%$ & $97 \%$ & $0 \%$ & $100 \%$ \\
pct.atu.strictu.pres & $3 \%$ & $0 \%$ & $84 \%$ & $3 \%$ & $0 \%$ & $100 \%$ \\
pct.atu.pesquisa & $18 \%$ & $0 \%$ & $100 \%$ & $15 \%$ & $0 \%$ & $100 \%$ \\
pct.bolsa.pesquisa & $2 \%$ & $0 \%$ & $91 \%$ & $2 \%$ & $0 \%$ & $99 \%$ \\
org.acad.cu & $17 \%{ }^{*}$ & - & - & $14 \%{ }^{*}$ & - & - \\
org.acad.fac & $73 \%{ }^{*}$ & - & - & $78 \%{ }^{*}$ & - & - \\
bib.portal.capes & $39 \%{ }^{*}$ & - & - & $40 \%{ }^{*}$ & - & - \\
bib.outras.bases & $66 \%{ }^{*}$ & - & - & $67 \%{ }^{*}$ & - & - \\
bib.servico.internet & $95 \%{ }^{*}$ & - & - & $95 \%{ }^{*}$ & - & - \\
\hline
\end{tabular}

* Proporção das IES que atendem ao valor Verdadeiro (1) da variável.

Fonte: Os autores (2019).

Pode-se verificar que a média de uma parte das variáveis permaneceu inalterada ou teve pouca variação entre um ano e outro. Esse é o caso de pct.ex, pct.mest, pct.dr, pct.regime.t.integral, idade.media, pct.atu.ead, pct.atu.extensao, pct.atu.gestao, pct.atu.grad.presencial, pct.atu.strictu.pres, pct.bolsa.pesquisa, bib.portal.capes, bib.outras.bases e bib.servico.internet.

A média do Enade das instituições (calculada como a média do Enade dos cursos por instituição) teve uma pequena queda entre um ano e outro. A proporção de IES que possuíam docentes com alguma deficiência caiu de $41 \%$ para $33 \%$. Outro dado revela que as instituições tinham, em média, $18 \%$ do quadro docente atuando em pesquisa em 2016, passando a ter 15\% em 2017. Pode-se verificar também que houve queda na proporção de centros universitários, ao contrário da proporção de faculdades. Essas diferenças são importantes, uma vez que estarão dentro da mesma regressão e 
podem ser determinantes para revelar razões para alterações do desempenho no Enade ou não.

Outras características que cabem ser mencionadas são as seguintes: 1) a menor proporção de docentes em exercício encontrada em uma IES subiu de $40 \%$ para $58 \%$; 2) quanto ao grau de escolaridade, os dados são mistos. O menor percentual de docentes mestres encontrados numa IES caiu de $10 \%$ para $0 \%$, enquanto o maior subiu de $87 \%$ para $100 \%$. Ao mesmo tempo, no caso de doutores, a proporção máxima subiu de $84 \%$ para $95 \%$; 3) a máxima proporção achada de docentes em regime de tempo integral em 2016 foi de $93 \%$, passando a $100 \%$ no ano seguinte; 4) a IES com idade média mais alta entre docentes subiu entre os dois anos; 5) a instituição com o máximo percentual encontrado de docentes que atuam em educação a distância subiu de $96 \%$ para $100 \%$; 6) o mínimo percentual de docentes que atuam em atividades de ensino em cursos de graduação presencial encontrado em 2016 foi de $29 \%$, ao passo que esse valor teve alteração significativa, passando a $0 \%$ em 2017; 7) o máximo percentual de docentes que atuam em pós-graduação stricto sensu presencial encontrado para uma instituição tinha sido de $84 \%$, valor que passou a $100 \%$ no ano seguinte; e, por fim, 8) a proporção máxima de docentes que tinham bolsa de pesquisa numa IES era de $91 \%$, ao passo que se encontrou em 2017 uma IES em que $99 \%$ dos docentes tinham essa bolsa.

Cabe lembrar que essas informações descritivas são válidas para as instituições que tiveram dados do Inep disponibilizados concomitantemente nas três categorias necessárias para a pesquisa: conceito Enade, microdados dos docentes e microdados da instituição.

Com todos os dados numa única base de dados, antes de rodar a regressão, passou-se a um teste de multicolinearidade, a fim de verificar se havia variáveis que poderiam trazer na essência a mesma informação e acabar gerando uma regressão instável, o que poderia levar a resultados incorretos. Para isso, foram calculados os fatores de inflação de variância (variance inflation fator - VIF) dos regressores. Como regra de bolso, pode-se considerar que um VIF acima de 5 indica a presença de multicolinearidade. Para as variáveis em questão, o máximo VIF encontrado foi de 3,54. Dessa forma, pôde-se seguir com a regressão pretendida. 
Na sequência, rodou-se a regressão e passou-se à análise dos resultados da pesquisa propriamente. Os coeficientes encontrados, bem como as informações a respeito das respectivas significâncias, podem ser encontrados na Fonte: Os autores (2019).

Tabela 2 - Resultados da regressão

\begin{tabular}{ccc}
\hline Variável & Coeficiente & Estatística t \\
\hline Intercepto & $2,11^{* * *}$ & 6,42 \\
pct.ex & $-0,31$ & $-0,65$ \\
pct.mest & $0,95^{* * *}$ & 8,24 \\
pct.dr & $1,44^{* * *}$ & 9,97 \\
pct.regime.t.integral & $-0,43^{* * *}$ & $-4,03$ \\
idade.media & $-0,32^{* *}$ & $-2,89$ \\
def & $0,15^{* * *}$ & 4,53 \\
pct.atu.ead & $-0,32$ & $-1,31$ \\
pct.atu.extensao & $-0,13^{*}$ & $-2,17$ \\
pct.atu.gestao & $-0,02$ & $-0,32$ \\
pct.atu.grad.presencial & $-0,17$ & $-0,48$ \\
pct.atu.strictu.pres & 0,21 & 1,12 \\
pct.atu.pesquisa & $0,18^{*}$ & 2,16 \\
pct.bolsa.pesquisa & $-0,18$ & $-0,81$ \\
org.acad.cu & $-0,03$ & $-0,42$ \\
org.acad.fac & $-0,19^{* *}$ & $-2,88$ \\
bib.portal.capes & $-0,02$ & $-0,75$ \\
bib.outras.bases & 0,03 & 0,84 \\
bib.servico.internet & 0,04 & 0,63 \\
\hline $\mathrm{R}^{2}=0,12$ e estatística $\mathrm{F}=15,05(p-v a l u e<0,000001)$ \\
* significante a $5 \%$ & \\
\hline & $* *$ significante a $1 \%$ & \\
\hline & $*$ significante a $0,1 \%$ &
\end{tabular}

Fonte: Os autores (2019).

O primeiro resultado a se verificar é que o $\mathrm{R}^{2}$ é baixo, o que indica que, embora as variáveis selecionadas expliquem $12 \%$ da variância da média do Enade, existem outras variáveis que explicam o resto da variância, tais como fatores advindos do próprio estudante (fatores cognitivos e sociais), outros fatores das instituições e demais atributos da docência não abarcados nesse modelo. No entanto, a estatística $F$ também indica que esse modelo de forma geral é significante, o que demonstra que se rejeita a hipótese de que todos os coeficientes sejam iguais a zero. Em outras palavras, as variáveis elencadas no modelo (principalmente as significantes) são explicativas para 0 conceito Enade, mas explicam parcialmente a variável dependente, sendo necessárias outras informações complementares.

Como todas as variáveis situam-se no intervalo entre 0 e 1, pode-se fazer uma comparação direta da magnitude dos coeficientes. Assim, em termos de sensibilidade, 
as variáveis mais sensíveis, ou seja, as de maior grandeza em valores absolutos, são as relacionadas ao grau de escolaridade. São elas que produzem os maiores efeitos sobre o conceito Enade no contexto do estudo. A mais irrelevante, levando-se em conta não só o coeficiente, mas em conjunto com a estatística $t$, parece ser a que relaciona $o$ percentual de professores que atuam na gestão e no planejamento (pct.atu.gestao).

Observa-se que, dentre as variáveis listadas e associadas à média do Enade, existe apenas uma que é significante e pertencente à IES, que é o fato de a IES ser uma faculdade, o que contribui de forma negativa com o desempenho no Enade, ou seja, pelos dados analisados, o fato de se tratar de uma faculdade está associado a uma diminuição em 0,19 na média do Enade da instituição. Todas as outras variáveis significantes dizem respeito ao perfil da docência.

As variáveis mais significantes estão relacionadas ao grau de escolaridade dos docentes. A proporção de docentes mestres e doutores está positivamente relacionada à média da instituição no Enade, resultado este esperado, uma vez que na literatura encontram-se resultados nesse mesmo sentido (tais como os citados na seção 2). Como o coeficiente de "pct.mest" é de 0,95 , isso significa que em média um aumento em $10 \%$ na proporção de mestres estaria relacionado a um incremento de 0,095 na média do Enade. Com a presença de doutores, esse efeito é ainda mais forte. Uma variação positiva de $10 \%$ na proporção de doutores estaria relacionada a uma variação de 0,14 na média da IES no Enade.

A título de ilustração e melhor compreensão sobre as variações produzidas na variável do Enade citadas anteriormente, considerando os anos de 2016 e 2017 estudados, um incremento positivo de 0,1 no conceito médio do Enade de uma IES que se situe no percentil 50 deslocaria essa instituição para o percentil 56 (aproximadamente), melhorando bastante sua posição em relação às demais.

Em seguida, o terceiro efeito mais significante é um surpreendente fator social: a presença de docentes com alguma deficiência. A existência de deficientes entre os docentes por si só respondeu na regressão por um aumento de 0,15 na média do Enade. Para que se possa compreender com mais precisão a razão para esse achado, sugerem-se, para pesquisas futuras, estudos mais aprofundados e confirmatórios a respeito desse fator. 
A variável seguinte está relacionada ao regime de trabalho do docente. Essa variável indica que, quanto mais docentes em regime de trabalho em tempo integral houver, menos isso contribui para a média do Enade. Esse resultado revela-se ao contrário do que era esperado, uma vez que se esperava que, quanto mais tempo um docente se dedicasse a uma IES, melhores seriam a qualidade do ensino e a absorção do conhecimento por parte dos discentes, já que os docentes estariam mais disponíveis aos estudantes; esse resultado também diverge do achado por Brito (2015). Uma explicação para essa divergência possivelmente vincula-se à abrangência e às limitações particulares de cada estudo (todos os estudantes, apenas estudantes de Administração, intervalo do estudo, universidades públicas, privadas ou ambas, entre outros). Pelo coeficiente encontrado $(-0,43)$, uma diminuição em $10 \%$ na proporção de docentes em regime de tempo integral levaria a um aumento em 0,043 na nota média do Enade das IES privadas. Pode-se aventar uma hipótese na qual talvez a extensão de tempo dedicada a uma instituição possa estar ligada à carga de trabalho. Docentes submetidos a regimes de trabalho com maior tempo de dedicação poderiam estar submetidos também a uma carga desproporcionalmente maior de trabalho, o que poderia influenciar a qualidade do ensino.

A idade média na docência é outro fator significantemente relacionado ao desempenho no Enade. O coeficiente indicado foi calculado para a variável de idade média normalizada. Fazendo a desnormalização, o coeficiente é de - 0,0116 para cada ano. Isto é, uma variação positiva de 5 anos na idade média dos docentes nas instituições indicaria uma variação negativa de 0,058 no desempenho do Enade das instituições. É uma variação pequena, porém estatisticamente significante, conforme o modelo. Esse resultado, de certa forma, também é contrário ao esperado, haja vista que seria esperado que IES com docentes mais experientes estariam mais bem capacitadas para levar os estudantes a maiores notas no Enade. Nesse caso, uma possível explicação para isso vincula-se às características próprias ligadas à idade, como, por exemplo, motivação. Profissionais mais jovens tendem a ser mais motivados, embora menos experientes, o que possivelmente é um atributo que produz algum impacto sobre os discentes.

Por fim, as duas últimas variáveis - menos significantes -, mas ainda com significância a 5\%, "pct.atu.extensao" e "pct.atu.pesquisa", cujos impactos são opostos. 
O coeficiente de "pct.atu.extensao" $(-0,13)$ indica uma relação inversa com a média do Enade, ao passo que o de "pct.atu.pesquisa" $(0,18)$ configura uma relação positiva. A magnitude dos coeficientes, entretanto, é pequena. De qualquer forma, o resultado indica que, com significância a 5\%, decréscimos na proporção de docentes que atuam em atividades de extensão, bem como aumentos na proporção de docentes que atuam em pesquisa no âmbito de projetos das IES, levariam a incrementos na média do Enade das instituições. As demais variáveis não são significantes nem mesmo a 10\%. Não obstante, cabe citar na sequência como as variáveis relacionaram-se, dado o contexto do estudo.

As seguintes variáveis estão positivamente relacionadas com a média do Enade: pct.atu.strictu.pres, bib.outras.bases e bib.servico.internet. Isto é, a proporção de docentes que atuam no stricto sensu presencial e o fato de as bibliotecas das IES terem acessos a outras bases ou oferecerem serviços pela internet contribuem positivamente para a média do Enade.

Por outro lado, as variáveis pct.atu.ead, pct.bolsa.pesquisa, bib.portal.capes, pct.ex, pct.atu.grad.presencial, org.acad.cu e pct.atu.gestao estão negativamente relacionadas à variável dependente, ou seja, o fato de a instituição ser centro universitário, de as bibliotecas terem acesso ao portal Capes e a proporção de docentes que atuam em cursos a distância, que têm bolsa de pesquisa, que estão em exercício, que atuam em cursos de graduação presencial ou que atuam em atividades de gestão, planejamento e avaliação não agrega valor ao desempenho dos alunos em relação à média do Enade das instituições. Cabe relembrar que não há significância estatística para os achados nestes dois últimos parágrafos.

\section{Considerações finais}

Este estudo buscou descrever as características que estiveram associadas ao desempenho dos estudantes no Enade de 2016 e 2017. Como variáveis, foram utilizados o conceito Enade médio por instituição (sendo a média do conceito Enade contínuo de cada curso) e atributos dos microdados dos docentes e das instituições, obtidos por meio do Inep. Como resultado, pode-se verificar que o fator mais relevante do perfil docente para o desempenho no Enade está no grau de escolaridade. Perfis docentes com graus 
mais altos de escolaridade (mestrado e doutorado) trouxeram contribuições positivas para o resultado apresentado pelos alunos no Enade. A inclusão de docentes com alguma deficiência também se mostrou positiva para o desempenho dos discentes. Em contrapartida, o regime de trabalho em tempo integral dos professores não demonstrou ter efeitos positivos sobre o conceito Enade.

Do ponto de vista educacional, os resultados mostraram que fatores do grau de instrução da docência tendem a melhorar o aprendizado ou a retenção de conhecimento por parte dos universitários. Ao mesmo tempo, um fator social, como a deficiência, também produziu efeitos nesse sentido, mostrando que as políticas educacionais (privadas ou públicas) de inclusão social (de profissionais com deficiência) trouxeram resultados positivos para o ensino, o que pôde ser verificado pelo desempenho dos estudantes. Outras características, como a dedicação em regime de tempo integral, a dedicação à extensão e a dedicação à pesquisa, têm reflexos sobre a qualidade do ensino.

No tocante aos aspectos da gestão, especialmente recursos humanos, como se trata de instituições privadas, os resultados mostram que decisões tomadas a respeito da docência teriam impactos sobre a qualificação dos estudantes. Uma forma de a gestão aproveitar tais resultados é focar os aspectos contributivos para o melhor desempenho dos discentes. Por exemplo, prover incentivos para a pós-graduação stricto sensu, incluir no corpo docente profissionais portadores de alguma deficiência, examinar a relevância do regime de tempo integral ou aperfeiçoá-lo, incentivar a atuação de docentes para a pesquisa. São decisões que contribuiriam para a imagem da instituição como empresa, uma vez que um melhor resultado dos estudantes seria publicizado, trazendo benefícios de mercado à instituição.

Cabe mencionar que os resultados deste estudo estão dentro de um contexto para o qual é necessário citar algumas limitações. O desempenho dos educandos explorado neste trabalho está baseado no Enade e traz consigo sua metodologia e suas próprias limitações. Esse exame, ao tempo que avalia o aluno, avalia também a instituição. É possível que algumas instituições e mesmo docentes acreditem que o bom desempenho dos estudantes está estritamente vinculado apenas à qualidade do corpo docente. No entanto, o conceito atribuído aqui a "desempenho" pode não ser necessariamente a melhor definição de desempenho dos estudantes das IES. O exame é realizado no fim do ano e o Censo da Educação Superior começa no fim do ano e a 
coleta de dados vai até abril do ano seguinte, o que representa apenas um ponto no tempo, um retrato da situação, que pode não representar adequadamente o conhecimento adquirido ao longo de vários anos dos concluintes ou o perfil da docência ao longo do tempo, por exemplo. Portanto, a regressão representa um marco no tempo, e não uma evolução. Por fim, os dados analisados referem-se apenas ao intervalo entre 2016 e 2017, logo os resultados retratam os fatos desse período.

\section{Referências}

BRITO, T, F. Corpo docente: fatores determinantes do desempenho discente no Enade. 2015. Dissertação (Mestrado em Administração) - Pós-Graduação em Administração, Universidade de São Paulo, São Paulo, 2015. Disponível em: https://www.teses.usp.br/teses/disponiveis/12/12139/tde-21032016-115045/pt-br.php. Acesso em: 20 jun. 2019.

FERREIRA, M. A. Determinantes do desempenho discente no Enade em cursos de Ciências Contábeis. 2015. Dissertação (Mestrado em Ciências Contábeis) - Pós- Graduação em Ciências Contábeis, Universidade Federal de Uberlândia, Uberlândia, 2015. Disponível em: https://repositorio.ufu.br/handle/123456789/12620. Acesso em: 28 jun. 2019.

GLEWWE, P. W. et al. School resources and educational outcomes in developing countries: a review of the literature from 1990 to 2010. National Bureau of Economic Research, Cambridge, p. 1-71, 2011. Disponível em:

https://www.nber.org/papers/w17554.pdf. Acesso em: 20 set. 2019.

INEP. Censo da educação superior. 2016a. Disponível em: http://download.inep.gov.br/microdados/microdados censo superior 2016.zip. Acesso em: 14 fev. 2019.

INEP. Censo da educação superior. 2017a. Disponível em: http://download.inep.gov.br/microdados/microdados educacao superior 2017.zip. Acesso em: 14 fev. 2019.

INEP. Conceito Enade. 2018. Disponível em: https://www.gov.br/inep/pt-br/areas-deatuacao/pesquisas-estatisticas-e-indicadores/indicadores-de-qualidade-da-educacaosuperior/conceito-enade. Acesso em: 28 jan. 2019.

INEP. Enade: Resultados. 2016b. Disponível em: http://download.inep.gov.br/educacao superior/indicadores/legislacao/2017/resultado en ade2016 portal 0609 2017.xlsx. Acesso em 30 jan.2019.

INEP. Enade: Resultados. 2017b. Disponível em: http://download.inep.gov.br/educacao superior/indicadores/legislacao/2018/resultados C onceito enade 2017.xlsx. Acesso em: 12 fev. 2019.

Educ. Form., Fortaleza, v. 6, n. 2, e4194, maio/ago. 2021

DOI: https://doi.org/10.25053/redufor.v6i2.4194

https://revistas.uece.br/index.php/redufor/index 
MIRANDA, G. J. Relações entre as qualificações do professor e o desempenho discente nos cursos de graduação em Contabilidade no Brasil. 2011. Tese (Doutorado em Contabilidade) - Programa de Pós-Graduação em Contabilidade, Universidade de São Paulo, São Paulo, 2011. Disponível em:

https://teses.usp.br/teses/disponiveis/12/12136/tde-16032012-190355/pt-br.php. Acesso em: 20 jun. 2019.

MIRANDA, G. J. et al. Determinantes do desempenho acadêmico na área de negócios. Meta: Avaliação, Rio de Janeiro, v. 7, n. 20, p. 175-209, 2015.

PIL, F. K.; LEANA, C. Applying organizational research to public school reform: The effects of teacher human and social on student performance. Academy of Management Journal, v. 52, n. 6, p. 1101-1124, 2009. Disponível em:

http://www.pitt.edu/ fritspil/pil\%20and\%20leana\%20ami.pdf. Acesso em: 20 jun. 2019.

SOUZA, C. A.; MOURA, V. F. A IES faz diferença? Análise dos determinantes de desempenho acadêmico dos cursos de Administração das instituições públicas no Enade 2012. FTT Journal of Engineering and Business, p. 17-35, 2017. Disponível em: journal.ftt.com.br/seer/index.php/FTT/article/view/60. Acesso em: 30 jun. 2019.

\footnotetext{
Alboni Marisa Dudeque Pianovski Vieira, Pontifícia Universidade Católica do Paraná, Departamento do curso de Pedagogia e Filosofia

i. https://orcid.org/0000-0003-3759-0377

Doutora e mestra em Educação. Professora dos cursos de Pedagogia e Filosofia da Pontifícia Universidade Católica do Paraná (PUCPR). Professora e pesquisadora do Programa de Pós-Graduação em Educação (mestrado e doutorado) da PUCPR.

Contribuição de autoria: $60 \%$ na administração do projeto; $50 \%$ na análise formal; $50 \%$ na conceituação; $20 \%$ na curadoria de dados; $20 \%$ na escrita - primeira redação; $80 \%$ na escrita revisão e edição; $20 \%$ na investigação; e $50 \%$ na metodologia.

Lattes: http://lattes.cnpq.br/0198429449537597

E-mail: alboni@alboni.com
}

\section{Daniel Schneiker, Pontifícia Universidade Católica do Paraná}

ii https://orcid.org/0000-0003-4881-0822

Mestre em Administração pela Pontifícia Universidade Católica do Paraná (PUCPR). Tem experiência na área de Machine Learning, métodos e modelos matemáticos/econométricos e estatísticos. Engenheiro elétrico.

Contribuição de autoria: $40 \%$ na administração do projeto; $50 \%$ na análise formal; $50 \%$ na conceituação; $80 \%$ na curadoria de dados; $80 \%$ na escrita - primeira redação; $20 \%$ na escrita revisão e edição; $80 \%$ na investigação; $50 \%$ na metodologia.

Lattes: http://lattes.cnpq.br/2129031448424415

E-mail: danielschneiker@hotmail.com

Editora responsável: Lia Machado Fiuza Fialho

Pareceristas ad hoc: Juvenilto Nascimento e Marilda Schneider

Educ. Form., Fortaleza, v. 6, n. 2, e4194, maio/ago. 2021

DOI: https://doi.org/10.25053/redufor.v6i2.4194

https://revistas.uece.br/index.php/redufor/index 


\section{Como citar este artigo (ABNT):}

VIEIRA, Alboni Marisa Dudeque Pianovski; SCHNEIKER, Daniel. O perfil docente no ensino superior privado e o desempenho no Enade. Educ. Form., Fortaleza, v. 6, n. 2, e4194, 2021. Disponível em: https://revistas.uece.br/index.php/redufor/article/view/4194

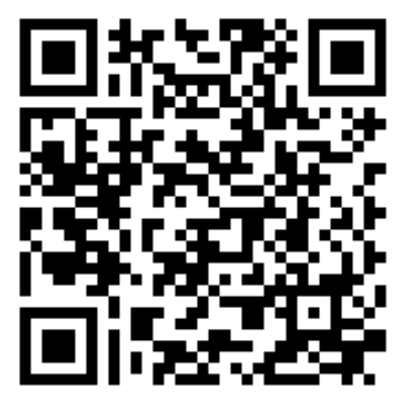

Recebido em 11 de outubro de 2020.

Aceito em 19 de dezembro de 2020.

Publicado em 11 de março de 2021. 